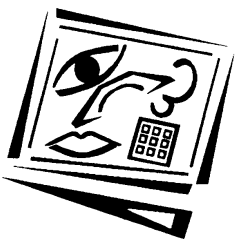

\title{
The potential for adaptable accessible learning objects: A case study in accessible vodcasting
}

\author{
Stavroula Gkatzidou and Elaine Pearson \\ University of Teesside
}

\begin{abstract}
With the rapid development of wireless networks and mobile technologies and the increasing adoption of mobile learning, the need for 'anywhere, anytime and any device' access to information becomes more evident. This has influenced the design of learning objects. The small but developing literature on vodcasting indicates its potential as an effective learning resource for use in education. This paper explores the use of vodcasting in terms of accessibility and, through a specific use case, investigates the adaptations required for existing learning objects delivered as vodcasts (videos downloaded to an MP3 player). The case study is examined in the context of a larger research initiative which aims to contribute to the requirements specification for the development of an adaptable learning object authoring tool, and suggests a learning object adaptation service which allows for flexibility and personalisation to learners' needs and preferences. Detailing the theoretical aims, design, implementation and evaluation of the project, the paper supports the argument for the educational use and value of vodcasting, but also highlights potential limitations and problem areas.
\end{abstract}

\section{Introduction}

In the present landscape of social and technological change, the shape of learning technology is currently being influenced by a number of forces, which present significant challenges for the learning designer. The increasing demand for new educational approaches and pedagogies, and the growing emphasis on the need to cater for the needs and preferences of the individual learner, are shifting the focus to the integration of adaptive and ubiquitous learning, in order to respond to the challenge of providing truly learner centred, accessible, personalised and flexible learning. Online learning can be a liberating and enabling experience for disabled students, providing that the environment is designed to meet the needs of the individual (Pearson \& Koppi, 2006).

Mobile learning capitalises on the increasing ubiquity of wireless network devices such as personal digital assistants (PDA), mobile phones, and video MP3 devices. With the rapid development of wireless networks and mobile technologies, mobile learning has become more achievable and more ubiquitous than ever before (Boulos, Maramba \& Wheeler, 2006). The pedagogical potential of mobile learning technologies include support for learning activities (Vavoula \& Sharples, 2001), catering to specific needs and cognitive abilities of diverse learning activities (Kukulska-Hulme \& Traxler, 2005), providing situated and authentic learning experiences (Sariola \& Rionka, 2003) and offering a personalised learning experience (Plant, 2001). For disabled students, these aspects of support, personalisation and flexibility can represent greater opportunities for participation. The notion of 'anytime, anyplace' learning has presented significant 
challenges to educators and learning technologists, and an impetus for learning to be delivered at the right time, at the right place and in the right form (Bomsdorf, 2005). It is widely recognised that in the current environment where mobile infrastructure is reaching the point of being pervasive, educators need to respond to the challenges for personal, accessible, and flexible learning. The focus of this research in the field of accessible mobile learning is influenced by our previous experiences in designing adaptable and accessible learning objects which could be accessed on a variety of different mediums and platforms (Gkatzidou, Pearson \& Jones, 2006).

Research has shown that the integration of adaptive learning with ubiquitous learning may offer great innovation in the delivery of education, allowing for personalisation and customisation to the learner needs (Jones \& Jo, 2005). With the development of the Internet has come the ability to easily deliver educational materials in electronic form to anyone, anywhere and anytime. Virtually any student, irrespective of disability, can be enabled to effectively interact with a computer (Nevile, Cooper, Treviranus \& Heath, 2005).

The widespread development and use of digital repositories for the storage and retrieval of learning objects over the web, the newly emerging IMS AccessForAll and Dublin Core adaptability and accessibility standards and the proposed profiles of needs and preferences (PNP), have also added new dimensions to the design of accessible learning resources. A key challenge in accessibility is the diversity of needs and it is essential to strive for e-learning to be available to all users, whatever their individual needs and preferences. In terms of access to or interaction with online learning resources, disability can be re-defined as a mismatch between the needs of the learner and the learning environment or education delivery (IMS AccessForAll, 2004).

This paper suggests an approach for learning designers to respond to these new challenges, by presenting the concept of a transformation, augmentation and substitution (TAS) service, which, incorporated within an authoring tool and a personal profiling system, could assist academics in designing adaptable learning objects. Starting from the vision of a ubiquitous learning experience, we aim to tackle the issue of adapting an existing learning object to be accessible on a mobile device, such as the PDA and the video MP3 player. The case study under discussion in this paper is part of a larger research study that aims to explore the creation of learning objects as a set of components that can be adapted to the needs and preferences of the individual learner. The paper begins by presenting the TAS service and discussing the case study. We go on to examine the issues and challenges of adapting for vodcast and discuss the findings of the case study. The following section pinpoints the limitations of this case study along with the challenges for this adaptation service. The final section considers the broader application of the adaptation service in designing and developing adaptable learning objects and identifies further research requirements.

\section{A transformation, augmentation and substitution service for adaptable learning objects}

In order to achieve an accessible relationship between the resource and the user, descriptions of user needs and preferences are checked against descriptions of resource components until they match. This process involves a description of a user's control, display and content needs and preferences being matched with a description of the components of the learning object (Nevile et al., 2005). The delivery of the appropriate 
component will form an accessible relationship between the user and the learning object. According to the AccessForAll metadata overview, accessible systems should be able to adjust the user interface of the learning environment, locate needed resources and alter resource properties to match the needs and preferences of the user. This may involve the substitution, augmentation or transformation of components of the resource, such as changes in sensory modality. For our purposes we propose a transformation, augmentation and substitution service (TAS) which is geared to a limited subset of e-learning applications and contexts. However this can be viewed as a special instance of an AccessForAll service.

Our work to date has focused on applying the TAS service to learning objects. To make rich online content match individual needs and preferences, this approach requires a basic resource to be created from existing or newly authored components, and the appropriate adaptations (transformations, augmentations and substitutions) need to be identified (Green et al, 2006). Examples of these adaptations are as follows:

Transformation:

Transformation may occur where text is rendered visually, as characters, or a sign

language, or aurally, perhaps by a screen reader, or transformed into a tactile form as

Braille or simply changed in colour, size and other display features.

\begin{abstract}
Augmentation:
Augmentation involves the optional addition of a feature to a primary resource, for instance a textual caption could be added to a video when required by a user with a hearing impairment or in a noisy environment.

Substitution:

Substitution might occur when a user requires a vision-free access to the resource, for instance if the user was accessing the learning object on a PDA on a field trip, to be accessible it is necessary to replace the visual element of the learning objects with components that match the user's preferences of vision-free access. Alternatively, an interactive exercise requiring a mouse for operation could be substituted by one that can be controlled using a keyboard or keyboard emulator for a user with a mobility impairment. (Pearson \& Jones, 2006)
\end{abstract}

\title{
Accessible learning vodcast case study
}

In order to investigate the requirements specification of the TAS service, it was necessary to examine a specific use case, which explored the requirements for the delivery of a learning object in different mediums. This case study was funded through the Higher Education Assistive Technology (HEAT) scheme administered by TechDis, the JISC educational advisory service on accessibility and inclusion.

This work is part of a larger research project in collaboration with the Learning Technology Research Institute (LTRI) at London Metropolitan University, which has carried out considerable work in the field of learning objects, placing a pedagogical emphasis on the design and development of multimedia learning material. The LTRI has developed a number of award winning learning objects and their successful use is well documented as part of innovative blended learning approaches to the teaching of programming to first year computing students (Boyle, 2003).

This particular case study has a twofold aim, first to identify and model the TAS service in terms of requirements for delivery of a learning object in different mediums - starting with a learning object originally designed for web delivery and adapted first 
for delivery on a PDA, and then for delivery with accessibility enhancements on a video MP3 player as a vodcast. The second aim is to explore vodcasting technology and its potential to support flexibility and accessibility in the learning environment.

\section{Background research}

The potential of the latest generation of Web 2.0 applications and their use in an educational context are receiving intense and growing interest across all sectors of the education industry (McLoughlin \& Lee, 2007). They are seen to hold considerable potential for addressing the needs of today's diverse students, enhancing their learning experiences through customisation, personalisation and rich opportunities for networking and collaboration (Bryant, 2006). Web 2.0 tools and particularly podcasts are being adopted by many educational institutions, as evidenced by the plethora of publications on the subject (Maag, 2006).

Podcasting is a fairly new method of web based broadcasting that may be used for automatically transferring digital audio or video (vodcasting) to portable media players. Vodcasting uses the enclosures of Really Simple Syndication (RSS) feeds for distribution of video content that can be downloaded to mobile devices. Mobile devices such as mobile phones, personal digital assistants (PDAs) and MP3 players are saturating the social environment of today's learners; yet, few of these devices have been adapted for use in educational applications, despite their significant interactive affordances and educational potential (Morgan et al., 2007). A number of studies have been carried out to evaluate the potential educational affordances of the $i$ Pod against a number of learning dimensions, with the iPod scoring high on 'study support' (Morgan et al., 2007), 'reusability', 'individual support' and 'scalability' (Oliver, 2007).

There is a growing body of evidence about podcasts being used effectively in education (e.g. Chan et. al., 2006; Tynan \& Colbran, 2006; Duke University, 2005; Maag, 2006; Miller \& Piller, 2007). In 2004, Duke University distributed iPod devices to its commencing students, pre-loaded with orientation information, with evaluation results revealing a positive reaction and great adoption rate by the students (Duke University, 2005). Since then, other universities have also established podcasting projects to include a diverse range of audio material ranging from lectures and audio books to language study. Drexel University distributed iPod Photo players to its first year education students, encouraging them to discover their advantages as a learning and teaching medium (Read, 2005). Georgia College and State University provide audio material ranging from lectures and audio books to language study and have created a full virtual learning community, termed "The iVillage", to connect Apple technology with related sources such as WebCT. One example of podcast integration is a war and politics course, where the faculty have students listen to Civil War ballads on an iPod (Our iPod Story, 2006). Purdue University has created BoilerCast which are audio recordings of classroom lectures (http://www.itap.purdue.edu/tlt/Boiler cast/), and at the University of Connecticut, faculty provide podcasts for pre-lecture material and a post-lecture discussion with students in the tutor's office (http:// web.uconn.edu/millerd/iCube.html). In addition, digital audio with portable audio players offers new possibilities for lifelong learning outside the academic classroom (Pownell, 2004). Stanford University is looking beyond their current students and are giving alumni and others access to lectures and other campus events (The Sounds of Stanford, via the iPod, 2005). 
If effectively deployed, podcasts could offer a way to enhance students' learning experiences and deepen levels of learner engagement and collaboration (Boulos et al, 2006), but there remain a number of issues concerning the educational use of vodcasting. Although a large number of studies have been conducted into the educational uses of podcasting, the existing educational uses of vodcasting are considerably limited. Current studies focus on the use of the technology to deliver instructional content such as lectures, which can lead to questions of pedagogical soundness and the risk of adversely affecting class attendance (Chan et al., 2006). 'Talking head' vodcasts can be tiresome and lengthy for the user and not pedagogically valuable. Vodcasting may enhance learning and encourage students to engage with material, but in order for it to add yet another modality of learning, vodcasts need to be designed and implemented appropriately. Empirical research is needed in order to compile pedagogical evidence about the use of vodcasts in the educational context and their potential in terms of accessibility is largely unexplored.

\section{Research methodology}

An action research approach was adopted for this case study of problem definition and analysis (plan), development (act), trial and evaluation of results (observe) and consideration of the implications of the results to the wider study (reflect) ( $\mathrm{O}^{\prime}$ Brien, 2001).

The preliminary stages of the project involved the analysis of existing learning objects which had been developed by LTRI with focus on navigation, interactivity, design and content issues, to establish the limitations to accessibility and adaptability to different devices. Analysis of structural and pedagogical aspects of the learning object has also identified the underlying learning design pattern that has been followed throughout the design of the learning object. Once this had been completed, the vodcast adaptations were defined and the learning objects were then re-developed taking into account the technical considerations of the portable media players. The prototype vodcast was then converted to an appropriate format, loaded onto the portable devices, and evaluated by students. This evaluation process consisted of semistructured interviews on an individual basis with participants. The results of this study will contribute towards our research work on developing tools for the creation of adaptable learning objects.

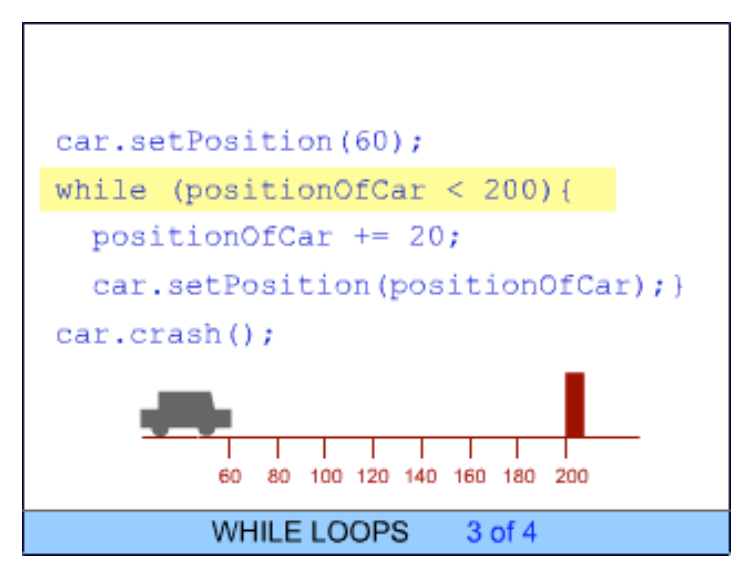

Figure 1: Screenshot from the vodcast 
The sample learning object used for this project was developed by the Learning Technology Research Institute (LTRI) and designed to help first year undergraduate students at London Metropolitan University learn JAVA programming. The While loop learning object was chosen to be used in the study; it is a short, self contained resource authored in Macromedia Flash which contains a single learning objective and explains an abstract programming concept that students find difficult to comprehend.

A number of multimedia techniques were employed to engage the students in the subject matter and to help them understand abstract programming concepts, such as animations and interactive simulations to provide visual examples of Java concepts and program code (Bradley \& Boyle, 2004; Jones, 2005). The learning object had already been adapted to be usable on a PDA, whilst retaining the multimedia richness and pedagogy of the original, but offering a more flexible, mobile alternative (Bradley, Haynes \& Boyle, 2005). The While loop learning object consists of an introductory page, three pages with examples and an interactive quiz at the end.

\section{Adaptations for vodcasting}

Two portable media players have been used during the project; the Apple Video iPod and the Creative Zen Vision M, both of which have a capacity of 30 GB and support a variety of different file formats. Both devices have a screen size of 2.5 inches and neither of them supported navigation through a touch screen. The Apple iPod offers navigation through the use of scrollwheel and the Creative Zen through the use of a control pad.

A number of adaptations were required for the PDA version of the While loop learning objects to be accessed on the portable MP3 devices which are presented in Table 1. The vodcast may be viewed at:

http: / / rime.tees.ac.uk/arc/vodcasts / while_loop_vodcast.m4v or

http:/ / rime.tees.ac.uk/arc/vodcasts/while_loop_vodcast.mp4

\section{Evaluation}

The web based version of the learning object which was used for this vodcasting study has already been used as part of an innovative blended learning approach to the teaching of programming and has been thoroughly evaluated by over 600 first year computing students (Bradley \& Boyle, 2004).

The main findings of that study indicate a very positive reaction to the learning object and an improvement of the pass rates. As a result this work has culminated in the achievement of a European Academic Software Award (EASA) in 2004. The PDA version of the learning object has also been thoroughly evaluated by a number of students, receiving positive comments for the 'interactivity' and 'multimedia elements' of the resource, as well as for the added dimension of 'flexibility' the PDA device has offered in their learning (Bradley, Haynes \& Boyle, 2005). The results of these evaluations demonstrated the pedagogical effectiveness of the learning object and therefore we could confidently use it to focus on testing the effectiveness of the adaptations for the MP3 players. 
Table 1: Learning vodcast adaptations

\begin{tabular}{|c|c|c|}
\hline $\begin{array}{c}\text { Type of } \\
\text { adaptation }\end{array}$ & Description & Discussion \\
\hline \begin{tabular}{|l|} 
Design \\
adaptations
\end{tabular} & 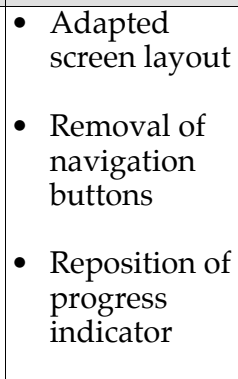 & $\begin{array}{l}\text { Since the While loop learning object had already been adapted } \\
\text { to a PDA version the number of design adaptations required } \\
\text { for viewing on a portable media player were minimal;. The } \\
\text { screen layout remained similar; the only content changes } \\
\text { made were to the navigation buttons, which were removed, } \\
\text { and the page title and progress indicator were moved from } \\
\text { the bottom to the top of the screen to accommodate captioning } \\
\text { at the bottom for the captioned version. The vodcast canvas } \\
\text { size was changed to match the screen size of the portable } \\
\text { media players (as the screen size of the PDA is larger than } \\
\text { that of the portable media players). }\end{array}$ \\
\hline \multirow[t]{2}{*}{$\begin{array}{l}\text { Pedagogical } \\
\text { adaptations }\end{array}$} & $\begin{array}{l}\text { - Removal of } \\
\text { interactive } \\
\text { elements }\end{array}$ & $\begin{array}{l}\text { Navigation of the PDA version of the learning object was } \\
\text { facilitated through buttons activated by the device's touch } \\
\text { screen. None of the portable media players used in the study } \\
\text { featured a touch screen and as a result, the interactive } \\
\text { elements would be unusable on the portable media players. A } \\
\text { navigation mechanism could not be provided through the } \\
\text { learning object itself, but the user could still use the general } \\
\text { controls built into the device, such as play, pause and stop. }\end{array}$ \\
\hline & $\begin{array}{l}\text { - Removal of } \\
\text { interactive } \\
\text { quiz }\end{array}$ & $\begin{array}{l}\text { The PDA version contained an interactive quiz, in the form of } \\
\text { a drag and drop activity which required the user to construct } \\
\text { an example while loop by selecting lines of code in the correct } \\
\text { order. The inclusion of a quiz in some form was examined, } \\
\text { but it was decided it could not be effectively implemented } \\
\text { without support for interaction within the timescale of this } \\
\text { project }\end{array}$ \\
\hline $\begin{array}{l}\text { Technical } \\
\text { adaptations }\end{array}$ & $\begin{array}{l}\text { File format } \\
\text { conversion } \\
\text { (AVI. to } \\
\text { MPEG4) }\end{array}$ & $\begin{array}{l}\text { The current generation of portable media players do not } \\
\text { support Flash movies and although Macromedia Flash has the } \\
\text { capability to export to .AVI format, we encountered } \\
\text { compatibility problems when using QuickTime. The video iPod } \\
\text { and the Creative Zen media players support a number of } \\
\text { different formats but the only file format which is supported } \\
\text { by both is MPEG4. }\end{array}$ \\
\hline $\begin{array}{l}\text { Accessibility } \\
\text { enhancements }\end{array}$ & $\begin{array}{l}\text { Closed } \\
\text { captioning }\end{array}$ & $\begin{array}{l}\text { The current generation of portable media players cannot read } \\
\text { a separate text-based caption file in the way that media } \\
\text { players can with web based video. Therefore the captions } \\
\text { were created with Apple's QuickTime Pro media players and } \\
\text { were added to the vodcast with the aid of Media Access } \\
\text { Generator (MAGpie).This text was then added to the vodcast } \\
\text { as a separate text track, and was exported as an .m4v file, in } \\
\text { order to combine the caption text with the video file, so it } \\
\text { could be displayed on both media players. }\end{array}$ \\
\hline
\end{tabular}

\section{Evaluation methodology}

The While loop vodcast has been evaluated in depth with representative users in order to provide feedback on their experience of using the vodcast and how this experience could be improved, as well as the potential of video MP3 players as a learning tool. A total of 13 participants took part in the evaluation and their demographic data is reported in Table 2 . 
Table 2: Demographics data $(\mathrm{n}=13)$

\begin{tabular}{|l|l|c|c|}
\hline \multicolumn{1}{|c|}{ Demographics } & & Sample & Percentage \\
\hline \multirow{2}{*}{ Gender } & Male & 10 & $77 \%$ \\
\cline { 2 - 4 } & Female & 3 & $23 \%$ \\
\hline \multirow{2}{*}{ Age } & Over 20 & 11 & $85 \%$ \\
\cline { 2 - 4 } & Over 35 & 2 & $15 \%$ \\
\hline \multirow{2}{*}{$\begin{array}{l}\text { Previous experience using a } \\
\text { portable video MP3 device }\end{array}$} & Yes & 7 & $54 \%$ \\
\cline { 2 - 4 } & No & 6 & $46 \%$ \\
\hline \multirow{2}{*}{$\begin{array}{l}\text { Language } \\
\text { Previous experience in Java }\end{array}$} & English & 9 & $69 \%$ \\
\cline { 2 - 4 } & Overseas & 4 & $31 \%$ \\
\hline \multirow{2}{*}{ Accessibility requirements } & Yes & 2 & $15 \%$ \\
\cline { 2 - 4 } & No & 3 & $85 \%$ \\
\cline { 2 - 4 } & Moaf & 1 & $8 \%$ \\
\cline { 2 - 4 } & None & 9 & $69 \%$ \\
\hline
\end{tabular}

The evaluation sessions were managed by a member of the research group who was not heavily involved with the project, in order to adopt a more objective approach. The evaluation instruments that have been used were structured interviews and questionnaires. The participants attended individually and after being introduced briefly to the case study, were given the MP3 players with the vodcast installed and a set of headphones and invited to take as much time as they needed to work through the learning object (which is about four minutes long). Afterwards, each student was interviewed using a standardised set of questions; while the deaf participants completed a questionnaire. The students were questioned on their views of the accessibility and usability of the vodcast, the pedagogical aspects, the appropriateness of the material for the device and their overall impression of the experience. The questions were framed in such a way as to support free text responses. Interviews were informal and students' responses were recorded over a period of one hour. The data collected from the interviews and the questionnaires was analysed and revealed a number of recurrent themes that are common to the three different user groups and their respective learning scenarios on their views of using the vodcast.

\section{Student opinions of the learning vodcast}

In terms of the content of the learning vodcast, $70 \%$ of participants commented on the high quality of the multimedia components. The combination of these components received more varied responses. Some users enjoyed the combination of multimedia content:

I liked being able to see the animation of the concept of the While loop, together with the bit of code.

Others felt 'distracted' by it. The participants who were studying Java gave positive feedback on the use of animated examples to explain the concept of the While loop. All the users agreed that the text size was appropriate (though none had vision impairments); and the vodcast was not too lengthy. In terms of access control for the device, only the participant with mobility impairments commented that:

It was hard to use the scroll wheel to control the volume.

while the rest of the participants had no problems in accessing the vodcast. 
The use of captions received a mixed response from the different participant groups. Captions were essential for the deaf participants in order to access the vodcast, and therefore their feedback was very positive. Comments included:

I have never seen anything like that before.

This is great, I didn't know I could have captions on iPod.

One deaf participant has however commented on the speed of the captions:

There was not enough time to read the captions.

The overseas students also expressed positive comments towards the use of captions, for example:

The captions helped me understand the concept better.

while the rest of the participants found the captions distracting. Both the captioned and non-captioned versions of the learning object were available to the participants.

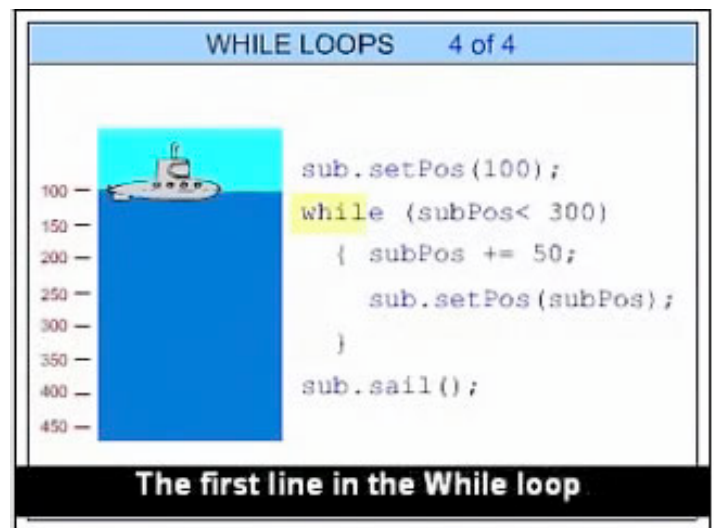

Figure 2: Screenshot from the captioned version of the vodcast

\section{How students would use the learning vodcast}

In terms of the potential use of learning vodcasts, the responses indicated that on average $85 \%$ of the participants agreed that they would use the vodcast as a form of learning material. Typical comments were:

I would use this as part of my independent learning (overseas student).

I would use this to help me with my exam revision (deaf student).

This evaluation also aimed to explore in what learning context the student would be most likely to use the vodcast. The results indicated that many students would use the vodcast for revision, but also as part of their weekly learning material and part of their independent learning and reinforcement of lectures (Table 3). Typical comments were:

This would be very useful when revising for my exams.

During lectures, I concentrate on my signer and I miss something the lecturer had said so the vodcast can supplement the lecture. 
Table 3: Use of vodcast evaluation results

\begin{tabular}{|l|c|c|}
\hline In what learning context would you use the vodcast? & Frequency & Percentage \\
\hline Exam revision & 6 & $46 \%$ \\
\hline Part of the weekly learning material & 2 & $15 \%$ \\
\hline Part of their independent learning & 1 & $8 \%$ \\
\hline As study support/reinforcement of lecture & 4 & $31 \%$ \\
\hline
\end{tabular}

However the participants also identified some disadvantages of using the iPod for learning; these were centred on the device itself, with cost being the main barrier (Figure 3).

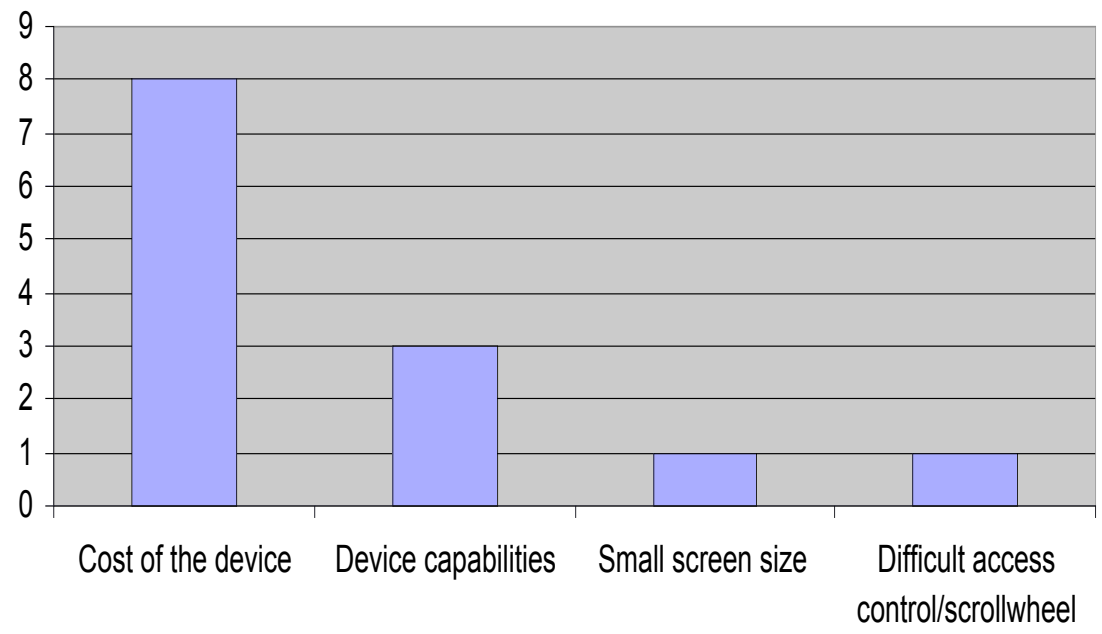

Figure 3: Disadvantages of using the iPod for learning

Only one participant has mentioned that adjusting to a smaller screen could be a problem. However the responses from the deaf students were more encouraging:

Until now, I thought that iPods were for hearing people, but now I can see that I could use one for my classes.

Although this was a small evaluation study, the data suggests that the vodcast is viable as an educational tool. The majority of students, including all the deaf participants, welcomed the idea of learning vodcasts and were willing to incorporate them into their study pattern and only one participant commented on the implications of small screen size.

\section{Discussion}

This project is part of a larger research study which aims to support the design of adaptable learning objects, by presenting the concept of a TAS service, which incorporated within an authoring tool could assist academics in designing fully inclusive learning material (Gkatzidou, Pearson \& Bailey, 2007). In order to be able to model the service and identify its vocabulary, it is essential to define the possible adaptations to the different components of a learning object. 
This case study has enabled the classification of the adaptations required for different forms of delivery in terms of the TAS service. For this example, we consider the web based version of the While loop learning objects as our original learning resource (Table 2.). This resource comprises a number of components: Flash animation, audio, text, interactive quiz. The following table uses the TAS to categorise the adaptations that were required for the web based learning object to be adapted to a PDA and to a vodcast version. We have included the requirements for a podcast version of the learning object for completeness, although that particular adaptation has not yet been implemented (Table 4).

Table 4: TAS adaptations table

\begin{tabular}{|c|c|c|c|}
\hline $\begin{array}{l}\text { Versions of } \\
\text { learning } \\
\text { object }\end{array}$ & $\begin{array}{l}\text { Transformation } \\
\text { (transformation } \\
\text { in display features) }\end{array}$ & $\begin{array}{c}\text { Augmentation } \\
\text { (optional addition of a feature } \\
\text { to a primary resource) }\end{array}$ & $\begin{array}{l}\text { Substitution } \\
\text { (replacement of primary } \\
\text { resource with equivalent } \\
\text { alternative resource) }\end{array}$ \\
\hline $\begin{array}{l}\text { Web based } \\
\text { version }\end{array}$ & --- & --- & -- \\
\hline $\begin{array}{c}\text { PDA } \\
\text { version }\end{array}$ & $\begin{array}{l}\text { - Screen layout } \\
\text { - File format } \\
\text { - Quiz screen layout }\end{array}$ & --- & $\begin{array}{l}\text { - Audio (to replace the } \\
\text { text) }\end{array}$ \\
\hline $\begin{array}{l}\text { Vodcast } \\
\text { version }\end{array}$ & $\begin{array}{l}\text { - } \text { Screen layout } \\
\text { - } \text { File format (Flash to } \\
\text { MPEG4) } \\
\text { - Interactive to linear }\end{array}$ & $\begin{array}{l}\text { - } \begin{array}{l}\text { Captions (to supplement } \\
\text { audio) } \\
\text { - Audio (for the captioned } \\
\text { version) }\end{array} \\
\end{array}$ & $\begin{array}{l}\text { - Audio (to replace the } \\
\text { text) }\end{array}$ \\
\hline $\begin{array}{l}\text { Podcast } \\
\text { version }\end{array}$ & $\begin{array}{l}\text { - File format (for video to } \\
\text { audio delivery) }\end{array}$ & $\begin{array}{l}\text { Sound effects/audio } \\
\text { description (to replace } \\
\text { visual effects) }\end{array}$ & $\begin{array}{l}\text { - Audio (replacement for } \\
\text { visual elements) }\end{array}$ \\
\hline
\end{tabular}

We suggest that the solution to developing adaptable learning objects lies in learning object authoring tools which would support the author in creating fully inclusive materials, by suggesting correct behaviours and sometimes imposing the completion of all additional information needed to ensure accessibility. Such a classification is important in terms of the capabilities that need to be built into an authoring tool to support the development of adaptable learning objects. By identifying the requirements for transformation, augmentation and substitution in this specific case study, the aim is to translate these to a requirements specification for other learning objects and to inform the development of learning object authoring tools and personal profiling mechanisms.

The TAS service will comprise two separate components, the adaptability component and the preference component, as shown Figure 4. This shows where the TAS service would fit within the learning object development process and the learner profiling process. The TAS adaptability component allows the author to identify alternative resources for specific learning object components. The learning object, its underlying pattern and its components will all be stored in the Learning Object Repository. The TAS preference component allows the user to create a Profile of needs and preferences (PNP), which would be stored in the PNP Repository.

The TAS service would be triggered by the user making a request through the Learning Object Repository. The service would then obtain the user's specified Profile of needs and preferences (PNP) and check the Learning Object Repository for the learning object's components in order to compare it with the PNP. Assuming the appropriate learning 
object components are stored in the repository, the TAS service will retrieve them, assemble them appropriately according to the learners' requirements and present the user with the adapted learning object. A prototype of the Learning Object Tutor Tools Interface (LOTTI) authoring tool has been developed with the integrated TAS Adaptability component and current work focuses on the development of the Profile for Adaptable Learning (PAL) profiling tool.

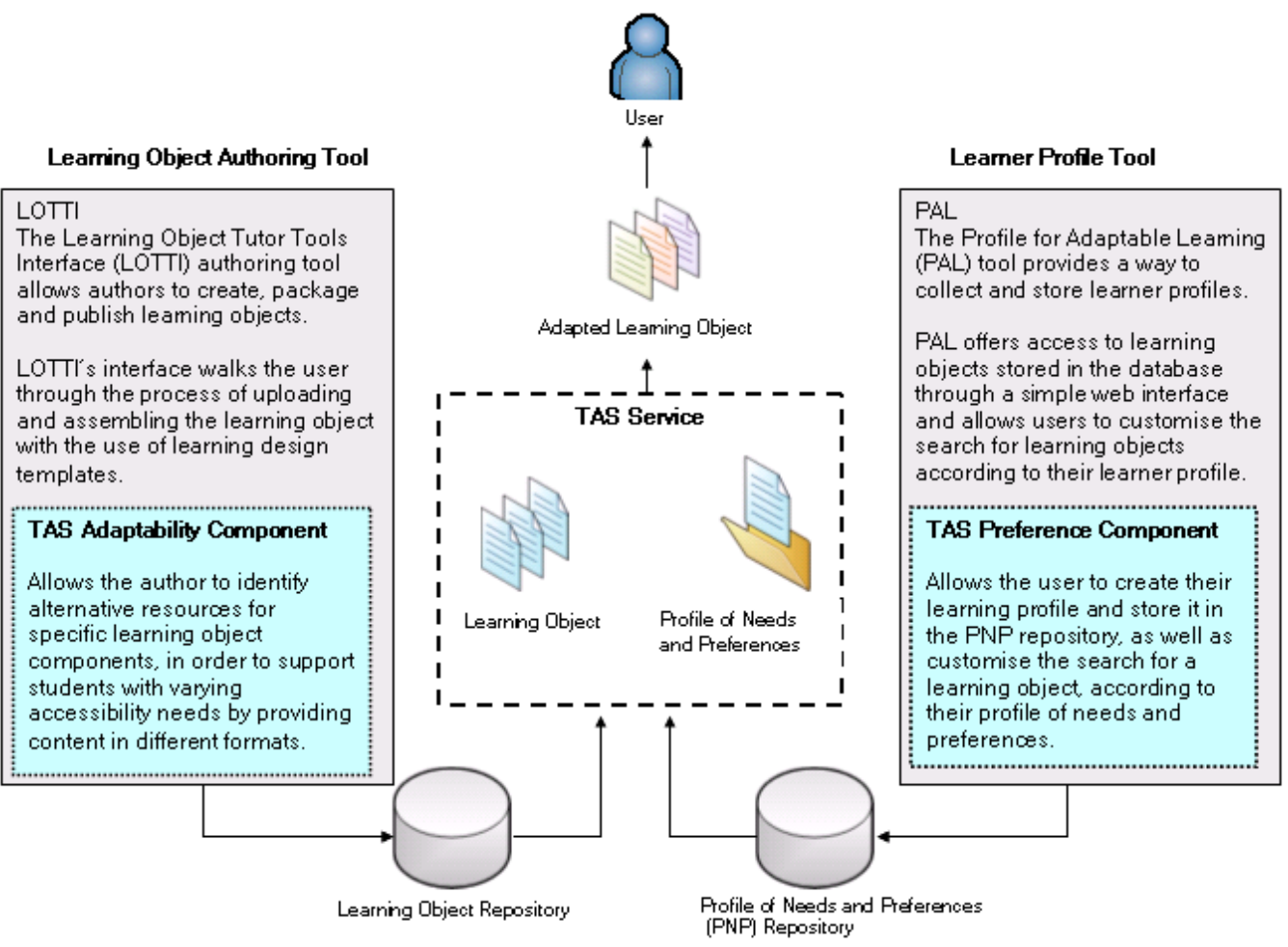

Figure 4: The TAS service model

\section{Limitations and future work}

Several limitations within this study must be taken into consideration when interpreting these initial findings. The small sample size of the results, the data that was collected in a snapshot of time and the limited exposure to vodcast limit the generalisation of these findings. In spite of these limitations, there are several key findings that may be helpful in designing a more rigorous research approach, in order to better understand the effectiveness of accessible vodcasting in education. A longitudinal evaluation would be helpful in establishing a set of metrics for measuring the effectiveness of vodcasting in an exclusive learning environment. In depth evaluations are also needed to identify further adaptations required for accessibility, to match different learning styles and to cater for other devices; and to examine whether the adaptations have compromised the pedagogical value of the original learning object. However, the latter question is beyond the scope of this particular project. 
The purpose of this case study has been to identify the requirements of the Transformation, Augmentation and Substitution adaptability component to inform the development of a learning object authoring tool, which incorporates this component. This case study has also enabled us to investigate the potential of accessibility profiles in the context of the development of learning objects and to explore the adaptability of learning objects based on user profiles. The next stage of this work is to explore the TAS preference component. The Profile for Adaptable Learning (PAL) tool, currently under development, aims to provide a way to create, store and edit a learner profile, based on the IMS Accessibility for Learner Information Package (ACCLIP) specifications (IMS, 2004). The PAL interface allows the learner to create, edit and modify their preferences regarding the appearance, layout and selection of content. In more detail the preferences include access requirements, content views, styling preferences and equivalent content requirements. PAL demonstrates the potential benefits of adaptable and personalised resources and tools for the learner and this further work will focus on exploring the practical boundaries of transformable content and the tools needed to support the creation of adaptable learning objects.

One of the limitations of adapting learning objects for the MP3 player is the lack of interaction and the linear navigation system afforded by the wheel mechanism. The research group is also exploring an alternative approach to adaptability whereby a different operating system is installed (Linux) on the iPod to support improved interaction and input methods otherwise not available on this device. This kind of adaptation enables the inclusion of elements in the learning object such as a drag and drop quiz. It also facilitates alternative input methods such as text prediction and a version of sign language. This research is however, at an early stage and beyond the scope of this paper.

\section{Conclusions}

In order to respond to the challenge of providing truly learner centred, accessible, personalised and flexible learning, this paper discusses the concept of a transformation, adaptation and substitution service by examining a specific use case, which explored the requirements for the delivery of a learning object in different mediums, by adapting a web based learning object to a PDA and vodcast version, as well as including enhancements for accessibility. The concept of a learning object as a vodcast has been well received, especially by deaf learners using captions, but further evaluation is required in order to determine its pedagogical effectiveness and more complex accessibility requirements.

By identifying the requirements for transformation, augmentation and substitution in this specific use case we can translate these to a requirement specification for other learning objects and inform the development of learning object authoring tools and of personal profiling mechanisms. The results from this study will be valuable in terms of exploring the requirements for adaptability of learning objects based on user profiles.

\section{References}

Bomsdorf, B. (2005). Adaptation of learning spaces: Supporting ubiquitous learning in higher distance education. In Mobile computing and ambient intelligence: The challenge of multimedia, Dagstuhl Seminar Proceedings. [verified 12 May 2009] http: / / drops.dagstuhl.de/opus/ volltexte/2005/371/pdf/05181.BomsdorfBirgit.Paper.371.pdf 
Boyle, T. (2003). Design principles for authoring dynamic, reusable learning objects. Australian Journal of Educational Technology, 19(1), 46-58. http: / / www.ascilite.org.au/ajet/ajet19/boyle.html

Bradley, C. \& Boyle, T. (2004). Students' use of learning objects. Interactive Multimedia Electronic Journal of Computer-Enhanced Learning, 6(2), Wake Forest University. [viewed 30 Apr 2009] http: / / imej.wfu.edu/articles/2004/2/01/index.asp

Bradley, C., Haynes, R. \& Boyle, T. (2005). Adult multimedia learning with PDA's: The user experience. Paper presented at the 4th World Conference on Mobile Learning, Cape Town, South Africa. [viewed 30 Apr 2009] http: / / www.mlearn.org.za/CD/papers/bradley-1.pdf

Bryant, T. (2006). Social software in academia. EDUCAUSE Quarterly, 29(2), 61-64. [viewed 30 Apr 2009] http: / / www.educause.edu/ir/library/pdf/EQM0627.pdf

Boulos, M., Maramba, I. \& Wheeler, S. (2006). Wikis, blogs and podcasts: A new generation of web-based tools for virtual collaborative clinical practice and education. BMC Medical Education, 6(41). [viewed 30 Apr 2009] http:/ / www.biomedcentral.com/ content/pdf/14726920-6-41.pdf\#search=\%22wikis $\% 20$ blogs $\% 20$ and $\% 20$ podcasts $\% 20$ boulos $\% 20$.pdf $\% 22$

Carleton University vodcast experiment. http:/ / www.carleton.ca/cutv/vod/vodcast.htm [viewed 30 April 2009]

Chan, A., Lee, M. \& McLoughlin, C. (2006). Everyone's learning with podcasting. In Who's learning? Whose technology? Proceedings ascilite Sydney 2006. http: / / www.ascilite.org.au/conferences / sydney06/proceeding/pdf_papers/p171.pdf

Duke University (2005). Duke Digital Initiative. iPod first year experience final evaluation report. Duke University, Durham NC, USA. [viewed 30 Apr 2009] http: / / cit.duke.edu/pdf/reports / ipod_initiative_04_05.pdf

EASA. European Academic Software Awards website. [viewed 30 Apr 2009] http:/ / www.bth.se/llab/easa.nsf

Gkatzidou, S., Pearson, E. \& Jones, R. (2006). The use of learning object patterns and metadata vocabularies to design reusable and adaptable learning resources. Paper presented at the World Conference on Educational Multimedia, Hypermedia and Telecommunications (EDMEDIA). Orlando, Florida.

Gkatzidou, S., Pearson, E. \& Bailey, C. (2007). Techdis Heat Project Report: An investigation of the potential for accessible vodcasting of learning objects. [viewed 30 Apr 2009] http: / / www.techdis.ac.uk/index.php?p=2_1_7_2

Green, S., Jones, R., Pearson, E. \& Gkatzidou, S. (2006). Accessibility and adaptability of learning objects: Responding to metadata, learning patterns and profiles of needs and preferences. ALT-J: Research in Learning Technology, 14(1), 117-129. http: / / repository.alt.ac.uk/104/1/ ALT_J_Vol14_No1_2006_Accessibility\%20and\%20adaptability.pdf [verified 12 May 2009]

IMS AccessForAll (2004). IMS Global learning AccessForAll project. [viewed 30 Apr 2009] http:/ / www.imsglobal.org/accessibility

Jones, R. (2005). Designing adaptable learning resources with learning object patterns. Journal of Digital Information, 6(1). [verified 12 May 2009] http:/ / journals.tdl.org/jodi/article/ view /60/62

Jones, V. \& Jo, J. (2006). Ubiquitous learning environment: An adaptive teaching system using ubiquitous technology. In Beyond the comfort zone: Proceedings ASCILITE Perth 2004. http: / / www.ascilite.org.au/conferences/perth04/procs/jones.html 
Kukulska-Hulme, A. \& Traxler, J. (2005). Mobile learning: A handbook for educators and trainers. Routledge, London.

Maag, K. (2006). Podcasting and MP3 players: Emerging education. Computers, Informatics, Nursing, 2(1), 9-13.

McLoughlin, C. \& Lee, M. (2007). Social software and participatory learning: Pedagogical choices with technology affordances in the Web 2.0 era. In ICT: Providing choices for learners and learning. Proceedings ascilite Singapore 2007.

http: / / www.ascilite.org.au/conferences/ singapore07/procs/mcloughlin.pdf

Miller, M., \& Piller, M. (2005). Principal factors of an audio reading delivery mechanism: Evaluating education use of the iPod. Paper presented at the World Conference on Educational Multimedia, Hypermedia and Telecommunications (EDMEDIA). Montreal, Canada.

Morgan, M., Butler, M. \& Power, M. (2007). Evaluating ICT in education: A comparison of the affordances of the iPod, DS and Wii. In ICT: Providing choices for learners and learning. Proceedings ascilite Singapore 2007.

http: / / www.ascilite.org.au/conferences/ singapore07/procs/morgan.pdf

Nevile, L., Cooper, M., Treviranus, J. \& Heath, A. (2005). Meeting the diversity of needs and preferences: A look at the IMS AccessForAll specifications' role in meeting the accessibility agenda efficiently. Accessible Design in the Digital World Conference. [viewed 30 Apr 2009] http: / / ewic.bcs.org/ conference/2005/ accessible/ workshops/workshop3.pdf

O'Brien, R. (2001). Um exame da abordagem metodológica da pesquisa ação [An overview of the methodological approach of action research]. In R. Richardson (Ed.), Teoria e Prática da Pesquisa Ação [Theory and practice of action research]. João Pessoa, Brazil: Universidade Federal da Paraíba (English version). [viewed 30 Apr 2009]

http:/ / www.web.ca/ robrien/ papers/ arfinal.html

Oliver, R. (2007). Using mobile technologies to support learning in large campus university classes. ICT: Providing choices for learners and learning. Proceedings ascilite Singapore 2007. http: / / www.ascilite.org.au/conferences/ singapore07/ procs/oliver.pdf

Our iPod Story (2006). Georgia College \& State University. [viewed 30 Apr 2009] http: / / ipod.gcsu.edu/GCSU\%20iPod\%20Story/index.html

Pearson, E. \& Jones, R. (2006). Designing adaptable learning resources. Proceedings of World Conference on Educational Multimedia, Hypermedia and Telecommunications 2006 (pp. 2985-2988). Chesapeake, VA: AACE.

Pearson, E. \& Koppi, T. (2006). A pragmatic and strategic approach to supporting staff in inclusive practices for online learning. In Who's learning? Whose technology? Proceedings ascilite Sydney 2006.

http:// www.ascilite.org.au/conferences/sydney06/proceeding/pdf_papers/p75.pdf

Plant, S. (2001). On the mobile: The effects of mobile telephones on individual and social life. Motorola. [viewed 30 Ap 2009] http:/ / www.motorola.com/mot/doc/0/234_MotDoc.pdf

Pownell, D. (2004). iListen, iLearn, iPod: Life-long learning with mobile audio. In C. Crawford, D. Willis, R. Carlsen, I. Gibson, K. McFerrin, J. Price \& R. Weber, (Eds.), Proceedings of Society for Information Technology and Teacher Education International Conference 2004 (pp. 1830-1831). Chesapeake, VA: AACE.

Read, B. (2005). Seriously, iPods are educational. The Chronicle of Higher Education, Section:Information Technology, 51, 18 March. 
Sariola, J. \& Rionka, A. (2003). Mobile learning in teacher education: The LIVE Project. In H. Kynaslathi \& P. Seppala (Eds), Mobile learning. Helsinki, FI:IT Press.

The sounds of Stanford, via the iPod (2005). Inside Higher Ed, October. [viewed 30 Apr 2009] http:/ / www.insidehighered.com/news/2005/10/21/itunes

Tynan, B. \& Colbran, S. (2006). Podcasting, student learning and expectations. In Who's learning? Whose technology? Proceedings ascilite Sydney 2006.

http: / / www.ascilite.org.au / conferences / sydney06/ proceeding/pdf_papers/p132.pdf

Vavoula, G. N. \& Sharples, M. (2001). Studying the learning practice: Implications for the design of a lifelong learning support system. Paper presented at the IEEE International Conference on Advanced Learning Technologies (ICALT). Madison, USA

Stavroula Gkatzidou and Elaine Pearson

Accessibility Research Centre

School of Computing

University of Teesside

Borough Road, Middlesbrough TS1 3BA, United Kingdom

Email: s.gkatzidou@tees.ac.uk, E.Pearson@tees.ac.uk

Web: http: / / rime.tees.ac.uk/ARC/ 